\title{
El MERCosur en la estrategia de Poder Global Brasileña $(2003-2010)^{*}$
}

\section{mercosur in the Brazilian Global Power Strategy (2003- 2010)}

Celeste Box

\section{RESUMEN}

En estas líneas presentaremos la dinámica de cooperación hegemónica que signó la relación de Brasil con la región suramericana durante la administración Da Silva. Este objetivo nos insumirá algunos desarrollos intermedios: en primer lugar, revisaremos la tan usual denominación del perfil 'realista' de la política exterior, para clasificarla como una estrategia de acumulación de poder externo en clave de power politics ( $y$ no de realpolitik) con componentes privativos (autonomía, diplomacia presidencial y autopercepción). En segundo lugar, y a fines argumentales, presentaremos la manera en que Brasil estructura esa estrategia de acumulación, por medio de un constructo analítico que denominamos 'estrategia de poder global brasileña'. Dentro de esta carrera -que excede la subregión-, haremos foco en el MERCOSUR para mostrar la superficialidad de la cooperación hegemónica del país vecino. Esto constituye un nuevo rol para la integración regional suramericana, impreso por la decisión de política exterior global de su miembro más poderoso.

\section{PALABRAS CLAVE}

MERCOSUR, Power politics; Cooperación hegemónica; Política exterior brasileña; Realismo.

\begin{abstract}
In this article we will focus on the Brazilian hegemonic cooperation towards South American integration in Da Silva's administration. To reach this before we must discuss two things: for one hand, to revisit the largely point out Brazilian foreign policy as 'realist' to resignify it as an accumulation power strategy in a power politics matrix (and not a realpolitik one). This profile has had its very specific characteristics: autonomy, presidential diplomacy and a determined self-perception. For other hand, we need to show the Brazilian way to structure that accumulation strategy through an analytical construct that we denominated 'Brazilian global power strategy' -a decision that largely exceeds the South American regional space-. In this sense, we will make a zoom just to the MERCOSUR to, finally, point out the superficial kind of hegemonic cooperation that our regional neighbor had implemented in those years. Thus, MERCOSUR ended up in a completely new role absorbed in -and at the service of- the global interests of the most powerful member.
\end{abstract}

\section{KEY WORDS}

MERCOSUR, Power politics; Hegemonic cooperation, Brazilian foreign policy, Realism.

\section{INTRODUCCIÓN}

El fin de estas páginas es presentar el perfil superficial de la cooperación hegemónica de Brasil para con la región suramericana con el gobierno de Luiz Inácio Da Silva

\footnotetext{
* El presente artículo se centra en la parte de la hipótesis de la tesis de Magister en Integración Latinoamericana: "Un nuevo papel para el Mercosur: la integración regional subordinada a la política de poder brasileña (2003-2010)", con dirección del Dr. Raúl Bernal-Meza, defendida el 31 de agosto de 2018, en el Instituto de Integración Latinoamericana (Facultad de Ciencias Jurídicas y Sociales) de la Universidad Nacional de La Plata.
} 
(2003-2010). Para concretarlo, avanzaremos en un recorrido analítico con diferentes fines: en primer lugar, deslindaremos el supuesto realismo con que se ha denominado a la política exterior brasileña de entonces, para reemplazarlo por un perfil de acumulación de poder diferente, en clave de power politics y con unas características extrínsecas e intrínsecas determinadas. Esta distinción nos permitirá mostrar una construcción analítica que denominamos estrategia de poder global brasileña, que instrumenta la política activa y altiva del vecino (este constructo no define la política exterior brasileña de ese periodo, es decir, no es un sinónimo de ella, sino que muestra cómo se instrumentó la acumulación de poder). De corte global de suyo, tiene su capítulo para la región suramericana (que, por cierto, fue un espacio determinante como plataforma de lanzamiento al globo). Especificaremos el aspecto regional y así ingresaremos al fin último de estas páginas: mostrar el perfil de cooperación hegemónica brasileño para Sudamérica, al que hemos adjetivado de superficial, dado que el vecino sólo establece algunos requisitos de ese ejercicio.

\section{EL PODER COMO MEDIO Y FIN}

La política exterior brasileña durante la gestión Da Silva ha sido calificada de diferentes maneras, tanto en la literatura especializada como en análisis de índole periodística: se la ha descripto como pura realpolitik, como realista o bien neorrealista, y hasta términos como maquiavelismo han aparecido relacionados a ella. Lo curioso es que también se la ha señalado como una manera de grocianismo, dinámica en la cual los intereses no están necesariamente en conflicto, contando con un juego distributivo y productivo de las interacciones estatales -un sistema de unidades autónomas articulado en una comunidad de valores de reglas comunes- Existen, también, quienes han adjetivado el supuesto realismo brasileño: tal el caso de Sanahuja (2012) al concebirlo como híbrido ideologizado antes que un ejercicio externo puramente 'realista'. Sanahuja (2012) señala las particularidades de los sectores que constituyen su aspiración multilateral como una plétora de actores semipúblicos y privados-manufactureros, transporte y automotriz-, que acompañan al gobierno y al cuerpo diplomático en esta labor (a lo que se debe sumar el Banco del Sur, el impulso en seguridad regional, el involucramiento del BNDES para con el IIRSA). Además, que la posición de Brasil, según Ayllón y Viola (2006; citado en Sanahuja, 2012), puede verse como realismo pero es ineludiblemente ideologizado: una política exterior combinada con el regionalismo intergubernamental de baja institucionalización (González, 2011; citado en Sanahuja, 2012), que articula el 
enfoque westfaliano de Itamaraty y el portoalegrense del Partido Trabalhista, de corte nacionalista y autonomista (Gomes Saraiva, 2010). Y, ya por fuera del realismo, existen quienes lo signan más cooperativo, y por tanto de corte multilateral y grociano como afirma Domínguez Ávila (2009):

La búsqueda de liderazgo no implica, en modo alguno, aspecto hobbesianoexpansionista-militarista, pues esa hipótesis lo tornaría definitivamente inaceptable e impresentable dentro y fuera del país [...] se fundamentaría en la hegemonía suave y la emergencia pacífica. (p. 84)

Si tomásemos cualquiera de las denominaciones que lo califican de realista, existe algo que no siempre está implicado: las particularidades que ese realismo debería presentar si fuese ejercido por Brasil. Aquí encontraríamos dos componentes extrínsecos, heredados, pero no por ello menos ineludibles: el primero es una suerte de filogénesis, por así decirlo, en la que Da Silva se vincula con Rio Branco (BernalMeza, 2013), al mostrar una combinación de juego de poder combinado con baja política (un multilateralismo absorbido por la lógica del poder -al que Brasil pretendía reformar- $)^{1}$. De este modo el riobranquismo atávico recibió algo así como una pátina grociana (Bernal Meza, 2013). En segundo lugar, el componente que es ineludible desde entrados los noventa del siglo pasado a esta parte: el Estado logístico, ese post-desarrollismo interesado en superar las asimetrías y toda vulnerabilidad externa, procurando una acumulación de poder planteada en clave de reciprocidad y dispersión multipolar (por supuesto que con el fin de contrapesar la incidencia del hegemón hemisférico y global). El paradigma logístico implicó la afirmación y promoción de la agenda multilateral en el sistema internacional junto con la autonomía en política exterior (Cervo y Bueno, 2002), la defensa de una posición estratégica del Estado ante los desafíos de la globalización (Machado Vergani, 2014), esbozado con Cardoso de manera algo ecléctica (por su apego al liberalismo externo y desarrollo interno en una suerte de fusión de capitalismo puro con estructuralismo -Cervo, 2003), resultó más consolidado con Da Silva gracias a un ejercicio activo de la autonomía (Cervo, 2003). Operativamente, intentó disminuir la dependencia tecnológica y financiera junto con una fuerte intervención sobre la desigualdad social (Cervo, 2009), lo que implica,

\footnotetext{
1 Domínguez Ávila (2009) recupera una configuración atávica, la 'alianza no escrita' entre Estados Unidos y Brasil, una Entente Cordiale para liderar en el norte y sur americano, respectivamente (la expresión 'alianza no escrita' proviene de Bradford Burns [Cf. A Aliança não escrita. O Barão do Rio Branco e as relações Brasil-Estados Unidos, Rio de Janeiro, EMC, 2003].
} 
obviamente, una coordinación entre el desarrollo interno y la acción estratégica de Brasil, que no puede alcanzarse si no se potencia su incidencia en el orden global (Bernal-Meza, 2013). Así, las herramientas para la construcción de poder extra fronteras (la cooperación internacional, las alianzas estratégicas, la integración regional), subsumidas en la dinámica logística, hicieron del Estado brasileño una plataforma de lanzamiento ante un medio globalmente interdependiente (donde Estados Unidos pierde estabilidad hegemónica unilateral). Nada de esto es menor, como señala Bernal-Meza, dado que llega a quitar a Brasil de la periferia atávica para devenir, así, un Estado en transición a poder codearse con los integrantes más poderosos del sistema internacional (el G20, la OMC, los BRIC y la política de foro desplegada) ${ }^{2}$. En este sentido, Ferreira (2009) afirma que Da Silva perfecciona el paradigma logístico, al sobreponerlo a vulnerabilidades externas: Brasil constituye una sociedad articulada en confederaciones de clases con un Estado que apoya la realización de esos intereses sectoriales. Como ello depende de la dimensión interna y externa, el Estado se impone con el peso de la dimensión nacional sobre la política exterior y deviene agente de gobernanza global. Esa evolución, para Ferreira, es lo que permitió a la política exterior de la era Lula caminar hacia la madurez (2009).

Pero, como mencionamos en la introducción, recelamos que Brasil haya realizado efectivamente una política que categóricamente pueda ser denominada como realista (carece de las capacidades ofensivas y el prestigio en el sistema internacional para ello), por eso tomamos una expresión que refleja una ruta analítica de mínima, más modesta, circunscripta a la mera acumulación de poder. Sostenemos en ella la filiación riobranquista y la pátina de Estado logístico y a ellas le agregaremos tres características más intrínsecas a la gestión Da Silva (más adelante trataremos esto). Antes de abocarnos a ello es necesario retroceder un tramo y recuperar brevemente la noción de política de poder y, dentro de ella, las precisiones que indica la power politics.

Schwarzenberger, quien descontaba al poder como el principal elemento de la política de la sociedad internacional, caracterizaba la política del poder como un tipo de relacionamiento entre Estados en el que predominan algunas reglas de conducta: armamentos, aislacionismo, diplomacia de poder y de guerra. De este modo,

\footnotetext{
2 No por esto queremos plantear un panorama libre de conflictos: diferencias como las posiciones en la OMC, la cuestión del Consejo de Seguridad, las trabas al ingreso del alcohol están, también, entre las más determinantes.
} 
Schwarzenberger (1951) afirma: "Puede definirse la política de poder como un sistema de relaciones internacionales en que los grupos se consideran a sí mismos como los fines últimos; emplean, al menos con propósitos vitales, los medios más efectivos a su disposición y son medios de acuerdo con su peso en caso de conflicto" (p. 12). En un medio donde predomina el principio que reza 'donde no hay poder común no hay ley, y por tanto, no existe la injusticia', el poder será determinante (aunque no lo único: los Estados eligen otros grupos con los que relacionarse, por lo que el derecho y la moral existen -incluso regulan algunas relaciones interestatales (Aron, 1979)-, pero, desde ya, estarán limitados por su posición subordinada.

Recuperar la noción de política de poder implica, creemos, la precisión de las connotaciones de la power politics. Asumimos la distinción que establece Raymond Aron (1979), al señalar que esta carece de toda valoración (a diferencia de la matchpolitik que exalta el esplendor de la fuerza estatal -a la Treitschke, donde el Estado es potencia y prestigio, la unión de la justicia que requiere de la capacidad/necesidad de la guerra para sostenerla). De filogénesis norteamericana, apegada a la prudencia y la limitación de objetivos, sopesa las diferentes alternativas antes de decidir. Acepta con resignación el uso y la acumulación de poder para evitar males mayores (Aron, 1979). Para ella, los Estados alentados por su voluntad de poder se ven en rivalidad continua, pero no se enorgullecen de ello ni blanden un principio que lo justifique (moral, jurídico, consuetudinario o incluso divino). Aron recupera a Weber para graficar la lógica de su razonamiento cuando mostraba los orígenes del capitalismo vis à vis el hombre contemporáneo: "los puritanos querían ser profesionales, nosotros estamos obligados a serlo" (Weber, 2008, p. 286). La power politics es un mal inevitable, por lo que omitirla es un lujo que los Estados pueden darse sólo a un alto riesgo. También pierde la primacía de la política exterior y, por oposición al contractualismo liberal -que se conforma con el respeto por la ley y la moralidad-, los realistas definen a la política por el poder y no al orden internacional por la anarquía.

De este modo, pensaremos la dinámica de la política exterior de Da Silva como una acumulación de poder en clave de power politics, con unas notas privativas extrínsecas (riobranquismo y Estado logístico) y otras intrínsecas (autonomía, diplomacia presidencial y autopercepción), que trataremos a continuación. 


\section{ESTRATEGIA DE ACUMULACIÓN}

Recolocado el perfil de política exterior en una lógica de acumulación de poder en clave de power politics, y ya mencionados los dos componentes extrínsecos, ahondemos ahora en su interior, indagando las tres características determinantes en la acumulación de poder externa de la gestión Da Silva: el corte autonómico, la diplomacia presidencial y la autopercepción, propia de los análisis del realismo neoclásico. A partir de esta caracterización basal podremos, en un próximo apartado, plantear la estrategia de poder global brasileña.

\section{1. Autonomía}

Al introducir la perspectiva autonomista en la política exterior del vecino lusoparlante, nos es preciso detenernos en una sesuda aclaración teórico-epistemológica. El autonomismo y una perspectiva de política de poder gozan de una compatibilidad fluida ${ }^{3}$ : la Doctrina de la Autonomía constituye una visión realista de las Relaciones Internacionales (Bernal-Meza, 1994, 1998, 2005; Simonoff, 2012). Bernal-Meza (2013) asevera: "los conceptos y categorías usadas son los del realismo, donde la noción de juego de suma-cero en la política internacional implica disputa de poder [...] significa ampliar el margen de decisión propia [...] avanza el antiguo cliente; retrocede el antiguo dominante" (p. 49). La autonomía, antónimo de dependencia, alude también a una cuestión de posición y, por qué no, de perspectiva: está asentada en la periferia de la estructura de poder mundial: Bernal-Meza (2013) recupera a Simonoff al señalar que el planteo de Puig refería al desarrollo del interés nacional objetivado racionalmente, en un marco de asimetría entre América Latina y Estados Unidos. Ese interés nacional, en manos de la élite a cargo del Estado-nación, debía acontecer en el espacio que la generación de márgenes de maniobra le otorgase (Simonoff, 2012, citado en Bernal-Meza, 2013).

Es interesante atender una síntesis de esta perspectiva a manos de Juan Carlos Puig (Bernal-Meza, 2013), quien concebía la autonomía en un gradiente, un continuum, que recorría desde la plena autonomía, típica del sistema internacional integrado por individuos soberanos a la subordinación -indeseable- por disminuir los grados de

\footnotetext{
${ }^{3}$ Incluso, puede tener consecuencias teórico-ideológicas, como menciona Schenoni (2015): la convergencia del desarrollismo con el realismo neoclásico podría derivar en una suerte versión progresista del realismo. Creemos que es un aspecto interesante para enriquecer el acervo del paradigma.
} 
libertad de manera inversa al de los de la potencia dominante (si bien no toda imposición necesariamente es injusta, la práctica demuestra que la mayoría de las veces la justicia está ausente para el subordinado (Puig, 1986, p. 40, citado en BernalMeza, 2013). En menos palabras, la autonomía implica esa máxima capacidad de decisión propia que se puede lograr, teniendo en cuenta los condicionamientos objetivos del mundo real (Bologna, 1989, p. 293, citado en Bernal Meza, 2013). Es por esto que creemos necesario destacar dos aspectos de la concepción de Puig: por un lado, mostrar la práctica autonomista a partir de una comprensión de la realidad internacional -que en este caso será optar por la mayor capacidad de acción en el sistema-; y por el otro lado, atender a la relación entre viabilidad, autonomía e integración. Esto último no es otra cosa que la relación entre recursos y el convencimiento de la elite de avanzar hacia la autonomía, y desde allí hacia la integración, que implicará instaurar una entidad basada en un destino solidario de valores comunes ostentables ante el sistema internacional (aunque no necesariamente tienen que ser los de este (Bologna, 1989, p. 293, en Bernal Meza, 2013) y lo más probable es que no lo sean).

Ya pensando específicamente en nuestro caso, Actis (2014) aporta el dato clave: la autonomía es el aspecto de continuidad de la política exterior brasileña más destacable entre la administración Da Silva y las predecesoras. Tanto es así que decidir sobre la base de necesidades y objetivos propios sin limitaciones externas (Russell \& Tokatlian, 2013) ha sido un objetivo que incluso imperó durante las dos décadas de dictadura militar:

El imperativo del desarrollo económico, la búsqueda de la paz, la extensión del alcance geográfico de las relaciones exteriores, la restricción del poder de las grandes potencias -particularmente de Estados Unidos-, así como la construcción de un orden internacional más equitativo han sido aspectos presentes en el histórico accionar externo de Brasil. Ahora bien, las estrategias de Brasil para obtener una mayor libertad de maniobra en el sistema internacional han ido cambiando en las últimas décadas. (Actis, 2014, p. 198199)

Desde 2003, la autonomía adopta otra topología, por así decirlo: Vigevani y Cepaluni (2007) Ilamaron 'autonomía por diversificación' a la desagregación de opciones estratégicas, que multiplican las alianzas. La dinámica no implica necesariamente 
resistir al avance de los regímenes internacionales por medio de la afirmación soberana y el fortalecimiento endógeno de mercados internos (como había sido durante la dictadura), sino que es, en realidad, proclive a los regímenes internacionales, y asume la posibilidad de influenciar sus principios y normas, a través de alianzas con otros países en desarrollo y así cambiar la asimetría con el mundo desarrollado (Actis, 2014) por evitar todo alineamiento con hegemones (de cualquier alcance). Para el caso de la administración Da Silva, esto implicó las alianzas Sur-Sur, las regionales, los acuerdos con aliados no tradicionales como Asia Pacífico, África, Europa Oriental, China. Esta decisión fue vista como la materialización del principio universalista de la política exterior brasileña, al mantener relaciones con todos los países, allende su posición geográfica, régimen político-económico y relación con los poderes globales (Gomes Saraiva, 2011, p. 54; Actis, 2014). El fin es constante: aumentar la capacidad negociadora con los poderosos (Vigevani \& Capulini, 2007).

Pero la lógica no parece tan colectiva, o al menos, no implica la formulación de un conjunto de países pares que juntos pujaran posiciones. Este esquema brasileño tenía como condición tenerlo como líder. Vigevani y Caplini (2007) afirman que, además, ello tuvo sus costos: "La administración Lula Da Silva colocó sin mostrarlo, el tema en el debate político brasileño. El deseo de obtener un papel destacado en la región y entre los países en desarrollo fue introducido y, en parte se constató el costo que Brasil afrontó de parte de los países sudamericanos" (p. 324). Entre sus ventajas, se produjo efectivamente el cambio de percepción de la opinión pública: comenzó a ver un Brasil con una proyección global ya no reducida a lo económico, sino a una inserción sociopolítica digna de global player (Actis, 2014).

\section{2. Diplomacia presidencial}

Es bueno comenzar afirmando que la diplomacia presidencial no reviste un factor demasiado novedoso para Brasil: iniciada con Cardoso, Da Silva tomó la posta. No obstante, debemos precisar algunas cuestiones y luego retomaremos esta continuidad entre presidentes.

Como señala Sérgio Danese (1999), la diplomacia presidencial alcanza la: "conducción personal de asuntos de política exterior, además de las competencias o atribuciones de oficio, por parte de la presidencia o, en el caso de un régimen 
parlamentarista, por el jefe de estado y/o por el primer ministro" (p. 51) ${ }^{4}$. La noción de 'conducción' puede resultar ambigua, tal vez vaga. En realidad, hemos intentado respetar la traducción, sin evitarnos algunos problemas: Danese refiere a lo que en la gestión pública (doméstica) se define como responsabilización, una solución de compromiso para traducir la voz anglosajona accountability ${ }^{5}$, sin equivalente castizo. Para el autor, el fenómeno de la diplomacia presidencial acontece cuando el Poder Ejecutivo Nacional se involucra directa e intensamente en el proceso decisorio, allende los límites de lo habitual, sin descartar un uso por fuera de su objetivo, como es la promoción interna del mandato. Malamud agrega el mecanismo de la negociación directa como el recurso en el que es ineludible una interlocución a cargo del/la mandatario/a. Esto acerca su oficio a la diplomacia de cumbre ${ }^{6}$-alejando el dispositivo del estamento profesional/burocrático-, y permite poner en juego cuestiones domésticas (como también -creemos- puede hacer más permeable la política exterior y la opinión pública). Claro que también la posibilitan cualidades de diseño institucional: el presidencialismo contribuye a su ejercicio (Malamud, 2005), por lo que cuando le sumamos la diplomacia presidencial obtenemos el interpresidencialismo (Malamud, 2005), un dispositivo que involucra negociaciones directas entre poderes ejecutivos nacionales a la hora de tomar decisiones críticas o solucionar conflictos (esta cuestión resulta imprescindible de recuperar, dado que el MERCOSUR es, desde su inicio, un esquema power-oriented en lugar de rule-oriented (Malamud \& Rodríguez, 2013, p. 117). De hecho, en otro trabajo (2010), el mismo autor relaciona la proyección del perfil institucional -todos los miembros del bloque son presidentes-, con el magro desarrollo institucional regional.

Vale mencionar que cualquier alejamiento de la diplomacia tradicional implica, en países presidencialistas, cierto grado de presidencialidad en el ejercicio diplomático, y el aspecto crítico no reside ya en la participación del jefe de Estado, sino en las

\footnotetext{
${ }^{4}$ La traducción es nuestra

${ }^{5}$ Alude, en concreto, al deber de las administraciones públicas de rendir cuentas ante la ciudadanía, basado en el derecho que esta goza de controlar la acción de los gobiernos (Cf. CLAD (2000). La Responsabilización ("accountability") en la Nueva Gestión Pública Latinoamericana. Caracas, Venezuela: Centro Latinoamericano de Administración para el Desarrollo).

6 Jarque et al (2009) señalan que este dispositivo diplomático ha tenido un importante desarrollo en la región a partir de los setenta del siglo pasado desarrollando mecanismos de cooperación vinculados a la integración (por nombrar algunas: la Cumbre de las Américas, Iberoamericana, la Cumbre América Latina y el Caribe - UE, la del Grupo de Río y la Cumbre del APEC). Sin duda que nada novedosas, ya que bajo la configuración westfaliana encontramos la de Viena de 1815, las de postguerra decimonónicas, las de las conflagraciones mundiales y, por supuesto, aquellas bajo la esfera de la ONU.
} 
expectativas que su ejercicio produzca, en la presión política y en la visibilidad que otorgue con su actividad (Danese, 1999). Pero no por esto toda actividad presidencial acarrea una diplomacia de su tipo: existen competencias protocolares (usualmente establecidas por ley) que imperan sobre el cargo, por lo que el Poder Ejecutivo tendrá que cumplirlas sin excepción. Sin mencionar que, más allá de esas competencias, la actividad presidencial en asuntos de política exterior -especialmente a la hora de interactuar con otros mandatarios- estuvo siempre presente en la diplomacia tradicional: el relacionamiento entre Estados precisa de este acto de alto contenido simbólico (es decir, todo el universo de prácticas protocolares insertas en el ceremonial público de una Primera Magistratura) por fuera de toda obligación formal.

De este modo, es momento de introducir un aspecto propio -y nada menor- de la diplomacia presidencial: ella reacciona e informa a la opinión pública. Como menciona Falcão Preto (2006), lo hará al intentar cooptar sus fines, impresionar o dialogar con ella con algún propósito. La autora asevera que, incluso, algunas decisiones son tomadas exclusivamente en función de la opinión pública, aspecto que fisura de manera brutal la interioridad de la política exterior. No por esto podemos omitir las posiciones divergentes con respecto a su potencialidad explicativa: Guilhon Albuquerque (1996) desconfía del concepto de diplomacia presidencial, asegurando que, si pensamos en un Poder Ejecutivo actuando de manera activa en las relaciones internacionales por medio de foros, negociaciones o declaraciones, el concepto resulta poco prolífico, porque no agregaría mucho a la comprensión de un rol que las y los Primeros Mandatarios ejercen como parte de su investidura.

Acorde Barnabé (2012) esta diplomacia es un emergente de las complejas -y asimétricas- relaciones de interdependencia del mundo desde hace unos cuarenta años, junto con la multipolaridad cambiante posterior a la Guerra Fría, la conformación de las 'G' (G-4, G-20, etc.) y la búsqueda de soluciones conjuntas a problemas globales o regionales. Todo esto facilita el surgimiento de la diplomacia de cúpula, por lo que los presidentes adquieren protagonismo eclipsando incluso a las cancillerías (reducidas a roles más acotados). Aquí sostenemos que cualquiera fuese el juicio sobre el concepto, si acordamos que existe una porción de la diplomacia que excede a la que acontece en la de la cúpula y aún recae en la figura presidencial, tenemos que tener en cuenta algunas cuestiones: por un lado, arrastra a la agenda internacional a centrarse en la figura del Ejecutivo; por otro lado, exige una labor más en la Primera Magistratura que resta tiempo para su dedicación a cuestiones domésticas (pensemos 
tan sólo en las consecuencias derivadas de tomar en primera persona esta función: el tiempo asignado a viajes, el costo de los mismos, etcétera).

En cuanto a la práctica brasileña, como decíamos más arriba, no es Da Silva quien inaugura esta etapa de hiperactividad diplomática presidencial, sino su predecesor ( $\mathrm{y}$, de hecho, fue una impronta típica de Rio Branco al inicio del siglo pasado -Barnabé, 2012-). Cardoso, intelectual reconocido extra fronteras, tomó en sus manos la conducción del devenir externo del país y:

El gobierno de Fernando Henrique Cardoso fue una gran e inédita muestra de la diplomacia presidencia en Brasil [...] fue una combinación exitosa de, por un lado, un mayor poder nacional de país, gracias a la estabilización y a los atractivos representados por sus dimensiones económicas, incluyendo su participación en el Mercosur y por la apertura de su economía; y, por otro lado, la vocación y disposición personal del Presidente para protagonizar una diplomacia presidencial del estilo consagrado en la actualidad por los mejores liderazgos mundiales. (Danese, 1999, p. 9. $)^{7}$

En el caso de Da Silva, el dinamismo es llevado a un mayor nivel (Barnabé, 2012). Si bien el término 'diplomacia presidencial' no es aludido por el Presidente o su equipo posiblemente para diferenciarse de su predecesor-, el mentado activismo diplomático implica un carácter dinámico y multipresencial de Da Silva (Barnabé, 2012). De hecho él decidió, en primera persona, hacer de la política exterior un asunto de su gestión política en sentido amplio -es decir, a imbricar deliberadamente aquella con la política doméstica-. Podemos afirmarlo, sin temor a partir de la articulación de idénticos objetivos domésticos y globales, como el desarrollo o la equidad social nacional duplicados en su promoción extra-frontera (Marcondes de Souza Neto, 2012). A ello debe sumarse una actividad menos visible, más especializada: Da Silva también compartió con Itamaraty la formulación y la ejecución de la política exterior con sus asesores presidenciales directos (Marcondes de Souza Neto, 2012).

\section{3. Autopercepción}

Creemos que, en el perfil de la política exterior de Da Silva, la cuestión de la autopercepción de Brasil es un aspecto determinante. Actis afirma: "La forma en que los hacedores de política perciben al mundo y el lugar y rol de su país en el mundo

\footnotetext{
${ }^{7}$ La traducción es nuestra
} 
(autopercepción) son importantes a la hora de entender algunas conductas del Estado en materia de política exterior" (Actis, 2014, p. 199). La cosmovisión condiciona -y da cuenta- de unas creencias activas en el diseño de la política exterior. Cuando las creencias versan sobre el titular y no sobre aquello que le rodea, es decir, su autopercepción, se suma un componente inmaterial al análisis del comportamiento de un Estado en el medio internacional. Este es el ingreso del realismo neoclásico a la hora de entender el perfil de acumulación de poder de la gestión Da Silva, donde también las capacidades repartidas en el sistema internacional son determinantes en las políticas exteriores, pero ellas no prescinden de percepciones, capacidades y la operatividad doméstica (Mijares, 2015).

El neorrealismo se preocupó por desembarazarse de la intuición, de la fuente histórica y de los análisis basados en el criterio del autor para abrazar el método científico cualicuantitativo que aportó la impronta behaviorista de los sesenta del siglo pasado. Esta ganancia para el paradigma más sólido de las relaciones internacionales dejó de lado la impronta tradicional (apegada al análisis histórico-intuitivo) mientras se presenciaba el impulso de otros paradigmas de creciente importancia a partir de los ochenta. Con la vertiente neoclásica reingresa al herramental analítico realista, aspectos que suelen ser asociados al constructivismo como la psicología, la antropología y otras perspectivas cualitativas (Mijares, 2015). Creemos que este tipo de inclusiones va abriendo, cada vez más, la rigidez que se le achaca al paradigma y esto deconstruye, echa luz a la black box estatal neorrealista.

Amorim (2016) afirma que un patrimonio de recursos naturales, energéticos y la capacidad de producción de alimentos, hace de Brasil un país titular de inestimable valor estratégico. Un valor que debe ser conservado por medio de una defensa activa e indelegable (Amorim, 2016). La política externa, a su vez, está asociada a la provisión de bienes públicos -por vía de la paz mundial-, lo que obliga a Brasil a no permitirse ser mero espectador al sistema internacional, allende las distancias geográficas que lo separen de los poderes centrales (Albuquerque, 2006). Apela a Maquiavelo para hacer de los problemas del mundo una materia que Brasil no debería ignorar: "Pienso, aquí, en la advertencia de Maquiavelo, que dijo en sus discursos: los otros poderosos, que están distantes y no tiene relaciones con aquéllos, cuidarán del asunto como algo lejano, que no los afecta. Error en el que se mantienen hasta que el incendio se les aproxima, y cuando llega, no hay más remedio que apagarlo con las propias fuerzas, que ya no alcanzan, dado que aquél se tornó poderosísimo" (Amorim, 
2016, p. 79) ${ }^{8}$. Esta afirmación que Amorim coloca en el orden global interpelando a Brasil, alcanza a la política de defensa nacional. Asegura que, para instrumentarla, este país apela a la disuasión y la cooperación: la primera pretende minimizar el riesgo de hostilidades de adversarios eventuales (mientras asegura que Brasil no tiene enemigos), ante una posible injerencia por recursos u otro atentado a sus intereses. Retomaremos esta cuestión en el próximo apartado.

El 'realismo' brasileño ha sido señalado por Actis (2014) como el factor de discontinuidad en su política exterior (donde la continuidad residió, impertérrita, en la búsqueda de autonomía). Dado que a través de Amorim nos hicimos eco de lo que es, en realidad, una combinación de la lectura del medio internacional con la autopercepción de Brasil sobre su coyuntura, el análisis de Actis, al echar mano del realismo neoclásico nos ha resultado notablemente adecuado. Si tomamos la autopercepción y la cosmovisión de los hacedores de política exterior como la variable interviniente de ingreso de la dimensión sistémica a la unidad, y pensamos en el cambio producido por la llegada de Da Silva en 2003 -en un mundo donde afloran las multipolaridades- el tránsito a un nuevo equilibrio con nuevas potencias (Schenoni, 2015), el presupuesto de que el orden internacional dista del consenso (como lo fue para el perfil multilateral de Cardoso) se encarnó en el pensamiento del equipo de gobierno y el propio Poder Ejecutivo (Schenoni, 2015). De aquí a una política de acumulación de poder nada restaba para poner en práctica su perspectiva de la política global.

La lógica de la correlación de fuerza que impone el poder, involucró a la gestión en la búsqueda de grietas que permitieran ingresar a Brasil en el globo a pesar de la imposición de sus intereses nacionales de los poderosos (Marcondes de Souza Neto, 2014). Claro que el multilateralismo también fue un pilar de la gestión que inicia en 2003 -a los fines de sus diferentes concepciones del funcionamiento del globo, carente de principismo- y se lo subordinó al objetivo del cambio de relación de fuerzas vigente. Esta es la raíz de la reciprocidad que mencionamos más arriba en boca de Da Silva para el libre-comercio (su apuesta a una economía capitalista, sólo que de acuerdos igualitarios) que no expresa otra cosa que la búsqueda de reciprocidad en las relaciones interdependientes de la baja política (Cervo, 2008).

\footnotetext{
${ }^{8}$ La traducción es nuestra
} 
En este sentido, la mentada democratización de las relaciones internacionales, multipolar, poseía una característica nada menor y tal vez destacable: contacto y conciencia de las capacidades. Este realismo -que no hace del poder un aspecto normativo y mantiene contacto con la circunstancia estructural de Brasil-, fue invocado por Da Silva en unas palabras inaugurales en 2005 :

Brasil es un país con problemas sociales y sin medios importantes de proyección de poder militar en el plano internacional, entonces no podría aspirar a ser globalmente un actor pleno [...] Es evidente que riqueza y fuerza militar son expresiones de poder. Ellas no agotan, en tanto, la capacidad de acción e influencia que puede disponer un país [...] nuestro desafío es intentar entender cómo Brasil puede colaborar para la construcción de una nueva relación de fuerzas en la esfera internacional. (Actis, 2014, p. 203)

Creemos que esta posición de Da Silva padecía de una contradicción interna: mientras era consciente de las menores capacidades del país, a la hora de proyectarse en el medio internacional parecía olvidar esta diferencia. Esto decantó en un sesgo optimista (que podríamos verlo en la pretensión de la altivez) que Brasil veía plausible poder ejercer, sólo sustentado en el interés de jugar un rol, sin dar cuenta de las posibilidades que el sistema le deje implementar. Actis (2014, p. 203) toma las conocidas palabras del Presidente, también afirmadas por Amorim (2006): "En enero de 2003 cuando volvía de Davos le dije a Celso Amorim [...] Celso, nosotros estamos en condiciones de cambiar la geopolítica comercial y la política mundial” (p. 205) ${ }^{9}$.

Como menciona Actis, Brasil no modificó sus capacidades de poder, lo que sin duda varió fue su autopercepción. Y agregamos: no es en la grandeza del país donde varió aquella -otros mandatarios han conocido las potencialidades de Brasil, por cierto, bastante evidentes-, sino que la variación estuvo, en concreto, en su pretensión de capacidad, basada en su autopercepción. El quid de la cuestión reside en este aspecto crítico que el país (se) arrogue a partir de esa percepción, y el grado de ajuste que ella

\footnotetext{
${ }^{9}$ Aunque no parezca una recomendación propia de un artículo sobre integración regional suramericana, creemos necesario recomendar atender entrevistas y ponencias del propio Celso Amorim (accesibles de manera masiva en la Red) donde explícitamente menciona la política exterior de Da Silva como una superación del 'complexo de vira-lata', una expresión que literalmente alude al mestizaje, pero en realidad, designa la posición de inferioridad brasileña en relación con el resto del mundo (la expresión fue creada por el cronista Nelson Rodrigues en 1958 aplicada al fútbol, y que, con posterioridad lo sintetizó como 'um problema de fé em si mesmo' (Cf. Rodrigues, N. (2014): Complexo de vira-latas. Revista látrico, (34)
} 
tenga con el diagnóstico del sistema (a lo que habría que sumar la incidencia presidencial en las decisiones -que no por ello desplaza ciento por cien a Itamaraty ${ }^{10}$-). En pocas palabras, creemos existe un punto de fuga de la autopercepción. El de los deseos versus la realidad, que no es otro que los objetivos y la plausibilidad de ellos. Por definición, el Estado que comete este error en la estimación de las capacidades, allende las aspiraciones, el coto aparecerá a la hora de no poder concretarlas: el caso de la pretensión brasileña de alcanzar el Consejo de Seguridad, para lo que debería contar con apoyos regionales -obtenidos por vía de la hegemonía o la construcción de algún tipo de liderazgo regional-, ilustra el desacople entre los objetivos de Brasil y sus capacidades para desplegar y concretar las estrategias que lo acercan a él. Este no es el único problema que acarreó el mentado 'realismo' brasileño: Schenoni (2015) asegura con tino, invocando el criterio de Waltz de la primacía de los incentivos sistémicos a favor de un equilibrio, que los movimientos de Brasil darían lugar a un nuevo equilibrio multipolar. Ello implica, de suyo, grandes desequilibrios en los niveles sub-sistémicos/regionales. Por eso creemos que es atinado volver, una vez más, sobre la consistencia interna del perfil de acumulación de poder de la política exterior brasileña en la era Da Silva: si su interés hacia el globo no podía prescindir de la dimensión regional, resulta difícil ver la viabilidad de este fin (la emergencia global), si para alcanzarlo desordena el medio (la dimensión sub-sistémica). En otras palabras, puede ser desde complicado hasta imposible llegar a una meta si para ello es necesario alterar la configuración del camino a ella.

Antes de abandonar este tercer componente es preciso una aclaración con múltiples implicancias en estas líneas: hemos abordado aquí la importancia de la autopercepción en la conformación de objetivos de política exterior. Para eso nos valimos del realismo neoclásico, en aras de la consistencia del camino recorrido en este paradigma en estas líneas. Pero la ruta analítica requiere, por supuesto, construir una determinada autopercepción para la gestión Da Silva. Creemos que ella es rastreable con mucha facilidad en los discursos del Poder Ejecutivo, en la producción teórica de cancilleres y especialistas relacionados con Itamaraty, junto con la pátina que imprime la extracción petista. También creemos que esta es una suerte de

\footnotetext{
${ }^{10}$ Hemos mencionado más arriba la particularidad de la política exterior de Da Silva con la incorporación de actores no tradicionales como las coaliciones de interés domésticas, sindicales y los movimientos sociales. Sólo que este componente no tradicional no jugó el rol de un tercer actor de la política exterior a la par de los dos primeros. Sólo pudieron tener una injerencia mediata, a través de la posición portoalegrense de la hechura de la política exterior (Malamud y Rodríguez, 2013).
} 
'primera capa' de la construcción de esa autopercepción, es decir, la que trasparece en esos dispositivos discursivos políticos y coyunturales del período, a manos de los mismos hacedores de la política exterior o bien de analistas versados en el tema. Sólo para mostrar ejemplos: para la justificación del accionar de Brasil basado en atributos clásicos de poder -territorio, población, estructura económica-, encontramos el trabajo de 2006 de Souto Maior:

Es normal que un país de las dimensiones territoriales, demográficas y económicas de Brasil aspire a tener, en el escenario internacional, un papel más destacado de aquél que ha asumido hasta ahora. En este sentido, es aún más natural que, por su peso relativo, se perciba en cualidad de primus inter pares en América del Sur. (p. 57) ${ }^{11}$

Vale remarcar que la autopercepción es meramente descriptiva. En el caso de Da Silva, ha sido lo suficientemente altiva como para no dar cuenta de su talón de Aquiles (las capacidades estatales) pero puede, sin duda, ser también motivo de limitación si informa a los hacedores de política exterior que el Estado se encuentra fuera de posibilidades para tomar ciertas decisiones o asumir algún/nos rol/es:

Itamaraty, consciente de las debilidades que el país aún posee, evita adoptar prácticas regionales que permitan a las potencias grandes actuar de la misma forma con él. Tal vez en este punto reside la explicación para la paradoja de un país que aspira a ejercer el liderazgo subregional, pero renuncia a comportarse como líder: la consciencia de las debilidades sociales, de un país gigantesco. Una debilidad estructural que, desde la época de la esclavitud, limita nuestra inserción internacional. Este es el elemento oculto que fundamenta la noción de soberanía y no-intervención manifestada por Río Branco, San Tiago Dantas y Araujo Castro, y que aún posee gran apoyo en el Estado y la sociedad brasileña (Vizentini, 2001, pp. 65-66).

Pero que, en cualquier caso, arroja a Brasil a un determinado curso de acción, para el que se asume apto. Escogemos una acción al azar, en boca de Valladão (2012):

Para demostrar de modo evidente que se trataba de una demanda seria y justificada, era necesario probar, concretamente, que el país estaba decidido a

\footnotetext{
${ }^{11}$ La traducción es nuestra.
} 
asumir alguna responsabilidad en la manutención del orden internacional. Brasil asume la conducción de la Fuerza de Paz multinacional en Haití (MINUSTAH) [...]. Las tropas brasileñas tienen una tradición de participación en las misiones de paz de la ONU, pero nunca con esta relevancia y responsabilidad. (p. 183).

El punto determinante aquí reside, a nuestro juicio, en que a través de estos dispositivos discursivos políticos no se completa la construcción de la autopercepción que informa la política exterior en un momento dado. Es, como dijimos más arriba, solamente la primera capa. $Y$ por lo tanto debe ser sustentada en análisis más profundos, munidos de disciplinas y estudios externos a las relaciones internacionales. Una vez construidas esas percepciones (el plural no es casual) imbricadas, es necesario volver a 'encajarlas' en los parámetros del realismo neoclásico con el fin de no responder a otras perspectivas (como el constructivismo). Esta labor, onerosa a estas páginas -ahonda el análisis en un aspecto de uno de los componentes y puede, por el celo de avanzar en esa dirección granular, dispersar el punto de atención de aquél-, creemos debe ser tenida en cuenta a la hora de incorporar este componente en desarrollos ulteriores.

Por último, un agregado más: en este tramo de nuestro desarrollo ya tendremos que dejar de referirnos a la posición brasileña durante la gestión Da Silva como meramente 'realista'. La razón reside en que, en lo que respecta, presentaremos el perfil de política exterior brasileña de nuestro período en clave de acumulación de poder (en los términos que en la primera parte denominamos power politics). Habiendo construido lo que entendemos por realismo brasileño a través de estos tres últimos componentes, ahora debemos ponerlo en juego, es decir, cotejar de manera dinámica en que ese realismo actúa, y eso será la estrategia de acumulación de poder del año 2003 al 2010, a lo que nos dedicaremos en el próximo apartado.

Por último, dadas las limitaciones de espacio, al presentar la Estrategia de Poder Global Brasileña -una construcción analítica de un proceso macro estratégico externo que tiene diversos componentes de enorme complejidad y magnitud-, sólo nos abocaremos a la que es pertinente a estas líneas, la integración regional suramericana. 


\section{PODER GLOBAL COMO OBJETIVO}

Es preciso plantear la manera en que Brasil ha desplegado esa acumulación de poder de manera dinámica a lo largo de todo el período. Así pues, denominaremos Estrategia de Poder Global Brasileña (EPGB) a la decisión política ${ }^{12}$ de la administración Da Silva de construir una política exterior de acumulación de poder signada por la power politics, con el fin de recolocar el rol y la posición de Brasil en la estratificación global.

Esa acumulación, identificada con el interés nacional por vía de la autopercepción, implicó el despliegue de una ingeniería de autonomía diversificada (Vigevani y Cepaluni, 2007) de fuerte impronta presidencial, anclada en atributos de poder clásicos (esto es, el territorio, población y la solidez de la economía, tal como lo plantean Soares de Lima y Hirst (2006).

La EPGB se sustenta en dos aspectos:

1) El estructural, en el que Brasil instrumenta un atributo clásico -el territoriocombinado con el poder $^{13}$, posado sobre actores de magra incidencia individual, que serán aunados en la esfera de influencia brasileña con el fin de obtener réditos capitalizando la sumatoria de esa incidencia en su lógica de acumulación. La dimensión estructural se subdivide en dos componentes: a) el acotado, en la dimensión regional y sub-hemisférica -México hacia el sur-, representado por: i) el despliegue regional preexistente -el MERCOSUR-, la esfera de influencia directa brasileña que permite ampliar su ya generoso territorio a los bordes del bloque (lo que pone énfasis en el componente territorial por sobre el poder, pero este, también, se ve impactado por la autopercepción brasileña de su tamaño relativo, lo que implica una mayor ostentación de poder. En menos palabras: el MERCOSUR constituye los límites territoriales de influencia directa de Brasil $^{14}$. Y ii) el regionalismo brasileño (BernalMeza, 2010), donde la UNASUR es el ejemplo por antonomasia. Aquí el poder es un componente preponderante al territorio (fuerte inversión en el componente político-

\footnotetext{
12 Referimos a la capacidad legítima de cualquier gobierno de decidir avanzar hacia un norte [informado por componentes ideológicos, también, pero] que expresa el interés nacional, con o sin continuidades con las precedentes. No estamos aludiendo a la calificación 'ideológica' que se ha predicado de la política exterior de la gestión Da Silva, asociada tanto a la impronta del PT o bien a la portoalegrense en Itamaraty.

${ }^{13}$ Aquí no está ajeno el componente de autopercepción: recordemos la afirmación de Souto Maior (2006) acerca de la naturalidad que Brasil se proyecte al mundo.

${ }^{14}$ Ello no implica que haya contribuido al impulso y sostenimiento que el bloque precisó en casi una década.
} 
estratégico, bajísima institucionalidad, fortalecimiento de las relaciones en la región, clara toma de posición por la autonomía hacia el exterior de la región y gran injerencia de actores brasileños con miras estratégicas regionales (Sanahuja, 2012)). Al igual que en el MERCOSUR, el componente relegado no está ausente: ese poder extiende la influencia y por lo tanto, resulta tan fuerte como lo es de extenso su territorio. En menos palabras, la UNASUR inflama las ostentaciones de poder brasileñas al exterior de la región y, de hecho, condensa la estrategia de poder brasileña con mayor completitud y de manera más fiel que el MERCOSUR: constituyen el verdadero eje, el verdadero espacio intermedio, la explanada entre el Brasil ampliado (Brasil + MERCOSUR) y el globo ${ }^{15}$. Por otro lado, el componente extendido, un tendido de relaciones y redes en territorios no contiguos, representado por el tendido de relaciones y alianzas de diferente tipo alrededor del globo -como el G20, BRIC, IBSA-, la cooperación internacional, ayuda humanitaria y mediación para la paz.

2) El focal, anclado en diferentes ecosistemas de centros de poder mundial -OMC, ONU y otros foros, relación bilateral con Estados Unidos- en los que desplegó una estrategia de participación e involucramiento activo -acorde sus capacidades-, en un juego de baja política -comercio y misiones de diferente cualidad ${ }^{16}$.

Ambos aspectos, además de concomitantes, están imbricados: el aspecto estructural implica la condición previa y sustento que Brasil considera preciso para legitimar su acción focalizada (es decir, su concepción clásica de los atributos del poder especialmente el territorial-), líneas que se desarrollarán más adelante. Y los rendimientos de su labor focalizada deberían devenir en un retorno en términos de poder (y eventual legitimidad) para que ese aspecto estructural le permita ejercer el rol de hegemón (y eventual líder) en los diferentes escenarios estructurales.

Lo anterior precisa de una aclaración acerca de la perspectiva que tomamos a la hora de la construcción de la EPGB. Desde el punto de vista del titular, esto es, desde Brasil hacia el mundo (una lectura que quedaría por completo trastocada si pensamos

\footnotetext{
${ }^{15}$ La UNASUR pone en evidencia la EPGB: su cordón vital (MERCOSUR) y su espacio de ostentación (UNASUR), que no concluía en la conformación del bloque, sino que también precisaba del tendido estratégico que representaba la IIRSA, junto con otros aspectos infraestructurales, financieros y de defensa en los que Brasil estuvo dedicado la década pasada.

${ }^{16}$ En los términos que Russell y Tokatlian (2013) se refieren al soft balancing, es decir, la utilización de las instituciones internacionales, instrumentos legales y diplomáticos para contener el poder de las potencias mientras se afirman el/los intereses/es propios.
} 
esta misma estrategia desde la perspectiva de Argentina, desde la de Estados Unidos o desde la de un aliado estratégico en el Sur). Ello implica una consecuencia analítica: la EPGB es una carrera de acumulación de poder nacional hacia el globo porque implica la acumulación de poder inserta en la política exterior de un país en un momento dado del tiempo. Por esto mismo, la EPGB no reproduce ni es sinónimo de la política exterior brasileña en ese período, sino que pretende reconstruir la dinámica más general de la acumulación de poder que la atravesó. No es su diseño ni su reproducción: es sólo su perfil, la manera en que Brasil se dedicó a acumular poder, un dispositivo signado por una autopercepción, signado por la búsqueda de autonomía con la diplomacia presidencial a su servicio. Y, si es así, sus componentes están imbuidos de esa acumulación en términos egoístas: la concepción de las alianzas estratégicas se desembaraza de todo utopismo y aspiración de acción conjunta, los regímenes sólo se instrumentan para hacer previsible el medio externo, la integración sólo sirve como medio de provisión de un bien público u obtención de alguna ventaja como la de índole territorial-, pero no hay viso de otra lógica que no sea la del interés nacional. Queremos exponer aquí un Brasil que pone sobre la mesa una serie de herramientas y estrategias para engrandecer su rol y reubicarse en el globo. Se trata de él y del poder con el que cuente -y el que se pueda proveer-, no se trata del engrandecimiento de la región o de algún socio. Retomaremos esta cuestión en la exposición final y pondremos nombre al medio procurado (el poder) y al fin que se le otorga -los grados de libertad creciente en la asimetría global-, gracias a unas herramientas que Brasil toma para sí.

Por último, tenemos que mencionar el uso que aquí haremos de ella. No podremos desarrollar por completo todas las caras de la EPGB. El fin de estas líneas será utilizar la estrategia de acumulación de poder del vecino, para ver el impacto que esa acumulación tuvo en el Mercado Común del Sur. Por eso haremos foco a partir de ahora en esta perspectiva que imprimimos a su política para con la región, con el fin de encontrar las razones que expliquen su cooperación hegemónica superficial en la integración suramericana.

\section{IV.CONCLUSIONES}

Haber planteado la manera en que el poder y el territorio se combinan en la dimensión subregional de la EPGB (dimensión acotada del componente estructural), nos permite ver que la integración mercosureña oficia como un Brasil expandido cual lebensraum - 
un primer cordón concéntrico de influencia cooperativa superficial, con el fin de apropiarlo y fagocitarlo en un interés nacional que mira al escenario global. Esto se articula con la UNASUR que avanza a un atenuado hinterland ${ }^{17}$ (suerte de zona de influencia con preeminencia -que no regencia completa- brasileña). $Y$ un segundo cordón, menos denso, pero no por ello menos asertivo, determinado a expandir la influencia -que no la regencia completa- de Brasil y que pudo haber sido usado para implementar otras estrategias como algún tipo de soft balancing.

El nuevo rol para el MERCOSUR que le imprime la acumulación de poder que asume este país deviene en una hegemonía cooperativa superficial. Tomamos esta denominación de los análisis de Pedersen (2002) y le agregamos el adjetivo superficial para definir, caracterizar cómo y en qué términos ejerció su preeminencia en la región. Para comenzar, es preciso separar sus aspiraciones de sus resultados efectivos de acumulación de poder:

La teoría tradicional de estabilidad hegemónica retrata, por supuesto, a los hegemones como Estados poderosos, los que imponen holgadamente su voluntad por medios unilaterales y sin necesidad de establecer instituciones sólidas. Pero [i] qué acontece con los Estados relativamente poderosos, faltos de altos recursos o enfrentados a restricciones en su libertad de acción unilateral? (Pedersen, 2002, p. 681) ${ }^{18}$

Brasil inserta en su acumulación de poder global una lógica de preeminencia relativa en un medio de baja institucionalización como el MERCOSUR. Este tipo de hegemonía, de corte cooperativo en clave de Pedersen (2002), requiere de tres aspectos: un hegemón que comparte poder (power sharing) con los miembros más pequeños del bloque en la dimensión institucional (que debe ser también estable); que además conjuga poder (power aggregation), es decir, el apoyo de otros Estados de la región; y, además, actuar como un hegemón que se compromete a una estrategia política regional a largo plazo (con compromisos plasmados institucionalmente). Ninguno de estos componentes son estancos, todos pueden variar en intensidad

\footnotetext{
17 Tomamos ambos términos de la manera más laxa posible y despojados de todas las connotaciones históricas que tuvieron desde el siglo XIX a esta parte: el primero sólo como una estrategia de influencia regional, el segundo como un resultado postrero del éxito de esa influencia. No obstante, somos conscientes que sólo pueden ser usados como analogías: por ejemplo, el lebensraum establece una relación población/territorio que no aplica para el MERCOSUR.

${ }^{18}$ La traducción es nuestra
} 
acorde las ventajas que el hegemón obtenga a partir de lo que brinde a la región, en cuatro aspectos: a) adquisición de escala por la unificación de mercado -que redundará en eficiencia-, b) mayor estabilidad en términos de seguridad, c) ventajas a partir de la inclusión en obtención de recursos, y por último a partir de la difusión, como puede ser d) una región donde proyectar ideas (Pedersen, 2002) ${ }^{19}$.

Más allá de las diferencias de perfil, las intensidades de cada aspecto, las ventajas que obtenga, el fin es constante: el hegemón echa mano de un armado institucional (cooperativo) porque servirá a sus intereses sin apelar a la fuerza. Por cierto, no referimos a una mera subordinación. Es decir, Brasil no echa mano del MERCOSUR sólo porque le permite engrandecerse en términos económico-territoriales y así ostentar el poder que requiere un nuevo rol externo. La dinámica no resulta tan lineal, porque el poder no está sólo del lado de Brasil. Recordemos que Hurrell (2005) mencionaba los intereses relacionados con el poder (power related interests) a la hora de llevar adelante un proyecto de integración regional. El poder existe, inerva y sostiene a la integración entre todos los miembros. Por eso, el poderoso precisa de la legitimación de los otros, que es, la forma de poder de los débiles, por así decirlo (legitimar es una forma de poder, sólo que pasiva).

Brasil ha logrado contemplar la primera condición (power sharing), pero es difícil encontrar las otras: no ha contado con apoyo en la región para su EPGB focal (como en el caso del apoyo argentino para el Consejo de Seguridad (Cervo, 2006; Malamud, $2005,2010)$ ), y los compromisos institucionales duraderos en el bloque del sur fueron crecientes pero no del todo consistentes (Giacobone, 2016) ${ }^{20}$.

El regionalismo implica, para el Brasil de Da Silva [una de las formas de] expresión del interés nacional y [una de] las estrategias globales del más poderoso. El horizonte

\footnotetext{
${ }^{19}$ Alencar Domingues (2012) relaciona la hegemonía cooperativa con el concepto de Sean Burges de hegemonía consensual. De hecho, afirma que la una no funciona sin la otra, dado que la segunda implica la aplicación de presión indirecta o la creación de condiciones que harían, en apariencia, de las medidas políticas futuras una acción de los pares en pos de su propio interés. Esta persuasión normativa requiere de la difusión de ideas por parte del hegemón que converja a las suyas y atender, concomitantemente, la definición de patrones de conducta aceptables (que definirán, por supuesto, sus agendas).

${ }^{20}$ Es muy interesante lo que afirma acerca de esta dinámica: si la idea de una institucionalidad parecía estar presente (...) [en] un proceso diseñado desde y para los gobiernos nacionales y con escasa voluntad supranacional. Es así que algunos autores prefieren hablar de "aluvión" institucional, para dar cuenta de un crecimiento cuantioso, pero disperso y en ocasiones desordenado, del MERCOSUR. Cf. Giacobone, G. (2016). "Del 'Mercosur comercial' al 'Mercosur social'. Rupturas y continuidades". En: Informe Integrar 95. Recuperado de: http://www.iil.jursoc.unlp.edu.ar/textos/informe/integrar95.pdf
} 
regional resulta un complemento de su inserción internacional. Para eso debería esmerarse en construir un proyecto atractivo para los vecinos, que implica una construcción de un orden regional determinado (Pedersen, 2002; en Alencar Domingues, 2012), concretado según dos posibles estrategias: la hegemonía unilateral de la potencia regional, y así evitar toda interferencia decisoria de los pares salvo por las que imponga la dimensión doméstica (claro que esto estimula la resistencia de pares y el free-riding). Aquí Brasil estaría sólo preocupado por su carrera global. Por supuesto, no eligió este camino, oneroso, e imposible para sus capacidades. Y la otra opción -la intentada-, más cercana al liderazgo, desplegada asociativamente, coordinando un orden conjunto con los vecinos (que disminuye de suyo el free-riding, porque los costos y riesgos se encuentran repartidos -aun cuando lo estén asimétricamente-). Esta estrategia se apoya en reglas legítimas y estables -que las hará más sustentables en el tiempo-, lo que redunda en previsibilidad y permite la sinergia de poder intrarregional (recursos, prestigio) que puede traducirse en acción colectiva en el sistema internacional (Pedersen, 2002 en Alencar Domingues, 2012).

Este ejercicio, sucede sobre un dispositivo en que Brasil no se predispuso: la inversión sobre instituciones regionales. Curiosamente, Pedersen afirma que esta decisión incide sobre el mantenimiento de su condición (es decir, el orden regional que el hegemón precisa) sin enfrentarse a los pares directamente. Aquí reside la superficialidad con que juzgamos el perfil de hegemonía cooperativa brasileña: despliega una estrategia de poder -que, como está acorde a sus capacidades, en apariencia resulta 'más benevolente'-, pero no provee medios para cumplirla. Algo que por cierto lo favorecería, sería tan oneroso como retribuido: la titánica inversión de un sistema de incentivos y compensaciones regionales retornaría por la previsibilidad regional de la conducta de los pares, y así lograría mantener a la región subsumida bajo su esfera de influencia, mientras la utiliza a sus fines.

Creemos que este aspecto aparece impedido por la asignación de recursos (esfuerzo, tiempo) que requiere en el tiempo la construcción del regionalismo brasileño (BernalMeza, 2009) del que sólo desplegó la UNASUR, y por los condicionantes que imprimen la temporalidad de esta construcción (es decir, la decisión propia de la gestión Da Silva de implementar la acumulación de poder). Establecer incentivos adecuados y fructíferos, sortear dificultades, invertir en instituciones, son procesos que muchas veces exceden un período tan corto como menos de una década. De hecho, creemos que la opción de la gestión Da Silva de construir un regionalismo propio por 
fuera del MERCOSUR, y de baja incidencia institucional, guarda relación con esto: si vemos en la dimensión [sólo] política y escasamente institucional de la UNASUR un aspecto derivado -antes que una 'deficiencia'-, entendemos que este perfil era la manera más eficiente -para un corto plazo- de obtener réditos idénticos a partir de una conformación regional de esas magnitudes. Construir institucionalmente la UNASUR llevaría varias gestiones, negociaciones y acomodamientos en diferentes escenarios (regionales, hemisféricos y globales) en aspectos comerciales y no comerciales. Dotar de contenido político a un esquema le da una entidad más rápida que la construcción lenta, con marchas y contramarchas, compleja y plagada de contingencias que implica construir un régimen de integración regional.

Brasil atinó a un solo componente de la hegemonía cooperativa, por lo que ella no superó la superficie, la nata. La magra intensidad que implicó eludir el rol de paymaster y promotor institucional, resultó también contraproducente a sus propios fines de acumulación de poder: una EPGB que debía hacer del MERCOSUR su zona de influencia como espacio intermedio hacia el globo, requeriría de la atención necesaria para fortalecerlo. Y Brasil no se la otorgó. Pero hacerlo implicaba uno de los costes que señala Pedersen: el hegemón cede soberanía al ponderar la institucionalidad conjunta y limita así sus grados de libertad. El país quedaría, así, enredado en una paradoja: necesita de la región para acceder al globo, pero no la atiende y se debilita (aspecto con que se topará a la hora de necesitar una legitimidad de sus pares). Lo curioso es que tampoco puede decidir la estrategia contraria -invertir tiempo y recursos en la coordinación institucional-, porque, de ser exitosa, no podría poner al MERCOSUR al servicio de su interés nacional, dado que la fortaleza institucional se lo impediría.

Es necesario asentar, para terminar, que las decisiones estratégicas no están basadas sólo en el voluntarismo brasileño (o en sus atributos para ejercer una posición dominante). También están en la herramienta que utiliza: el MERCOSUR. Un bloque que ostenta componentes contradictorios: fundado en un marco de regionalismo abierto para reemplazar al proteccionismo del PICAB (Bernal-Meza, 2010), tuvo por objeto la creación de un mercado común (Ouro Preto, 1994) y un subsistema internacional (el Acuerdo Marco Interregional de Cooperación con la UE), pero que no lograría una potente creación de comercio sin desarrollo industrial y tecnológico (Ouro Preto, 1994). Tampoco se dotó de una política exterior común -o al menos coordinaday ello lo dejó reducido a una función económica, reducida sólo a aspectos comerciales. 
Este esquema queda, en 2003, a disponibilidad de Brasil (por supuesto que con esto no afirmamos que el MERCOSUR se redujo a mera herramienta de la acumulación de poder brasileña. El bloque siguió funcionando -bien o mal- bajo sus propios términos, pero sus debilidades -sobre todo de eficacia institucional- no hacen nada por evitar que el poder del miembro con más envergadura se imponga).

\section{BibLIOGRAFÍA}

Actis, E. (2014). Cambios dentro de la continuidad. Un análisis de la reciente política exterior brasileña (1990-2010). Íconos, $\quad$ (50), 195-208. https://doi.org/10.17141/iconos.50.2014.1437

Actis, E. (2015). La relación bilateral entre Argentina y Brasil (2011-2014). La confluencia de factores sistémicos y domésticos para una menor intensidad relativa en las interacciones. Estudos Internacionais, 3(1), 27-44. Recuperado de http://periodicos.pucminas.br/index.php/estudosinternacionais/article/view/9607

Albuquerque, J. A. G (2006). O governo Lula em face dos desafios sistêmicos de uma ordem internacional em transição. Carta Internacional, 1(1), 13-21.

Alencar Domingues, R. (2013). Uma Potência Regional em Construção? O Brasil na América do Sul durante os anos Lula (2003-2010). Revista Política Hoje, 22(2), 231248.

Amorim, C. (2016). Grande Estratégia do Brasil. Discursos, artigos e entrevistas da gestão no Ministério da Defesa. Brasília (2011-2014). Brasil: UNESP.

Aron, R. (1979). Paz e Guerra entre as Nações. Brasilia, Brasil: Universidade de Brasília.

Barnabé, I. (2012). O Itamaraty e a Diplomacia Presidencial nos governos FHC e Lula. Contextualizaciones Internacionales, (7), 1-9. Recuperado de http://www.contextualizacioneslatinoamericanas.com.mx/index.php

Bernal-Meza, R. (1994). América Latina en la Economía Política Mundial. Buenos Aires, Argentina: GEL. 
Bernal-Meza, R. (1998). As relações entre Argentina, Brasil, Chile e Estados Unidos: política exterior e Mercosul. Revista Brasileira de Política Internacional. 41(1), 90-108. Recuperado de http://www.scielo.br/scielo.php?script=sci issuetoc\&pid=0034732919980001\&lng=en\&nrm=iso

Bernal-Meza, R. (2002). A Política Exterior do Brasil: 1990-2002. Revista Brasileira de Política Internacional, 45(1), 36-71. Recuperado de http://www.scielo.br/scielo.php?script=sci issuetoc\&pid=0034732920020001\&lng=en\& $\underline{\mathrm{nrm}}=\mathrm{iso}$

Bernal-Meza, R. (2005). América Latina en el mundo. El pensamiento latinoamericano y la teoría de las relaciones internacionales. Buenos Aires, Argentina: Nuevo Hacer GEL.

Bernal-Meza, R. (2009). El Regionalismo: Conceptos, paradigmas y procesos en el Sistema Mundial Contemporáneo. Aportes para la Integración Latinoamericana, (21), 1-29. Recuperado de https://revistas.unlp.edu.ar/aportes/issue/view/320

Bernal-Meza, R. (2010). International thought in the Lula era. Revista Brasileira de Política Internacional, 53(spe), 193-213. Recuperado de http://www.scielo.br/scielo.php?pid=S0034-73292010000300012\&script=sci abstract

Bernal-Meza, R. (2013). Heterodox autonomy doctrine: realism and purposes, and its relevance. Revista Brasileira de Política Internacional, 56(2), 45-62. Doi: http://www.scielo.br/scielo.php?pid=S0034-73292010000300012\&script=sci abstract

Cervo, A. \& Bueno, C. (2002). História da Política Exterior do Brasil. Brasília, Brasil: UnB.

Cervo, A. \& Rapoport, M. (1998). História do Cone Sul. Rio de Janeiro, Brasil: Revan.

Cervo, A. \& Saraiva, J. (1998). (Orgs.). Le Brésil et le Monde: pour une histoire des relations internationales des puissances émergentes. París, Francia: Harmattan. 
Cervo, A. (2008). Conceitos em Relações Internacionais. Revista Brasileira de Política Internacional, 51(2), 8-25. Doi: https://dx.doi.org/10.1590/S0034-73292008000200002

Cervo, A. (2009). La construcción del modelo industrialista brasileño. Revista Diplomacia, Estrategia y Política, 10(2). Recuperado de: http://www.funag.gov.br/biblioteca/dmdocuments/Dep 10 espanhol.pdf

Cervo, A. L. (2003). Política exterior e relações internacionais do Brasil: enfoque paradigmático. Revista Brasileira de Relações Internacionais, 46(2), 5-25.

Danese, S. (1999). Diplomacia presidêncial: historia e critica. Rio de Janeiro, Brasil: Topbooks.

Recuperado

de

http://funag.gov.br/biblioteca/index.php?route=product/category \&path=62\&sort=pd.nam $\underline{\text { e\&order}=A S C \& p a g e}=20$

Dominguez Ávila, C. (2009). Brasil, el Gran Caribe y la reconfiguración de la agenda común: tendencias, desafíos y perspectivas en los primeros años del siglo XXI. Foro Internacional, 49(195), 69-93. Recuperado de https://forointernacional.colmex.mx/index.php/fi/article/view/1955/1945

Ferreira, W. (2009). Política externa do governo Lula: Coalizões ao Sul como alternativa multilateral. Revista Debates, 3(1). 100-125. https://doi.org/10.22456/1982$\underline{5269.8351}$

Giacobe, G. (2016). Del MERCOSUR Comercial al MERCOSUR Social. Rupturas y Continuidades. Informe Integrar, (95). Recuperado de: http://www.iil.jursoc.unlp.edu.ar/textos/informe/integrar95.pdf

Gomes Saraiva, M. (2010). Brazilian foreign policy towards South America during the Lula administration: caught between South America and Mercosur. Revista Brasileira de Política Internacional, 53, 151-168. http://dx.doi.org/10.1590/S003473292010000300009 .

Guilhon Albuquerque, J. (1996). A Presidência na linha de frente da diplomacia. Carta Internacional, 35(1), 110-122. 
Hirst, M. (2006) Los desafíos de la política sudamericana de Brasil. Nueva Sociedad (205), 131-140. Recuperado de https://nuso.org/articulo/los-desafios-de-la-politicasudamericana-de-brasil/

Hurrell, A. (2005). Book Review: Akira Iriye, Global Community: The Role of International Organizations in the Making of the Contemporary World. Journal of Cold War Studies, 7(1), 186-189. http://dx.doi.org/10.1162/jcws.2005.7.1.186

Jarque, C., Ortiz, M. S. \& Quenan, C. (Eds.) (2009). América Latina y la Diplomacia de Cumbres. Ciudad de México, México: Secretaria General Iberoamericana. Recuperado de https://www.segib.org/?document=america-latina-y-la-diplomacia-de-cumbres

Llenderrozas, E. (2009). UNASUR: Desafíos geopolíticos, económicos y de política exterior. Pensamiento Propio, (42), 195-214. Recuperado de http://revistasnicaragua.net.ni/index.php/pensamientopropio/article/view/3723\%20

Malamud, A. \& Rodríguez, J. (2013). Com um pé na região e outro no mundo: O dualismo crescente da política externa brasileira. Estudos Internacionais, 1(2), 167183.

Recuperado

de

http://periodicos.pucminas.br/index.php/estudosinternacionais/article/view/6312/5791

Malamud, A. (2005). Presidential diplomacy and the institutional underpinnings of Mercosur: An empirical examination. Latin American Research Review, 40(1), 138-164. Doi: https://doi.org/10.1353/lar.2005.0004

Malamud, A. (2010). Latin American regionalism and EU studies. Journal of European Integration, 32(6), 637-657. Doi: https://doi.org/10.1080/07036337.2010.518720.

Marcondes de Souza Neto, D. \& Abdenur, A. (2014). Rising powers and Antarctica: Brazil's changing interests. The Polar Journal, 4(1), 12-27. Doi: http://dx.doi.org/10.1080/2154896X.2014.913910

Mijares, V. (2015). Realismo neoclásico: ¿El retorno de los estudios internacionales a la ciencia política? Revista de Ciencia Política, 35(3), 581-603. Doi: http://dx.doi.org/10.4067/S0718-090X2015000300006. 
Miyamoto, S. (2000). O Brasil e as negociações multilaterais. Revista Brasileira de Política Internacional, 43(1), 119-137. http://dx.doi.org/10.1590/S003473292000000100006 .

Pedersen, T. (2002). Cooperative hegemony. Power, ideas and institutions in regional integration. Review of International Studies, 28, 677-696. https://doi.org/10.1017/S0260210502006770

Russel, R. \& Tokatlian, J. (2013). América Latina y su gran estrategia: entre la aquiescencia y la autonomía. Revista CIDOB d'afers Internacionals, (104), 157-180. Recuperado de https://www.cidob.org/articulos/revista cidob d afers internacionals/104/america latin a y su gran estrategia entre la aquiescencia y la autonomia

Sanahuja, J. (2012). Regionalismo post liberal y multilateralismo en Sudamérica: el caso de UNASUR. En A. Serbin, L. Martínez \& H. Ramazini. (Coords.). El regionalismo "post-liberal" en América Latina y el Caribe: Nuevos actores, nuevos temas, nuevos desafíos (pp. 19-72). Buenos Aires, Argentina: CRIES. Recuperado http://www.cries.org/wp-content/uploads/2013/03/anuario2012.pdf

Schenoni, L. (2012). Ascenso y hegemonía: pensando a las potencias emergentes desde América del Sur. Revista Brasileira de Política Internacional, 55(1), 31-48. http://dx.doi.org/10.1590/S0034-73292012000100003.

Schenoni, L. \& Actis, E. (2014). Argentina y Brasil: una unipolaridad regional con sesgo económico. Revista Sociedad Argentina de Análisis Político, 8(1), 207-235. Recuperado de http://hdl.handle.net/11336/29971

Schenoni, L. \& Jenne, N. (2015). Latin American declaratory regionalism: An analysis of presidential discourse (1994-2014), EUI Working Paper RSCAS, (2015/53), 1-25. Doi: https://doi.org/10.13140/RG.2.1.1467.3763

Schwarzenberger, G. (1951). Power Politics. A study of international society. New York, Estados Unidos: Frederick A. Praeger. 
Simonoff, A. (2012). Teorías en movimiento. Los orígenes disciplinares de la política exterior y sus interpretaciones históricas. Rosario, Argentina: Prohistoria Ediciones.

Soares de Lima, M. R. (2005). Aspiração internacional e política externa. Revista Brasileria de Comercio Exterior, 19(82), 4-19. Recuperado de http://www.funcex.org.br/publicacoes/rbce/rbce sobre.asp

Soares de Lima, M. R. (2007). Brasil como país intermedio: imprecisión conceptual y dilemas políticos. En J. Tokatlian (Comp.). India, Brasil y Sudáfrica: El impacto de las nuevas potencias regionales (pp. 169-190). Buenos Aires, Argentina: Libros del Zorzal.

Souto Maior, L. (2006). O Brasil e o regionalismo continental frente a uma ordem mundial em transição. Revista Brasileira de Política Internacional, 49(2), 42-59. Recuperado de http://www.redalyc.org/html/358/35849203/

Valladão, A. (2012): Los BRICS, ¿abridores de caminos o seguidores remisos?. Archivos del Presente 16(59), 120-140

Vergani Machado, D. (2014). A política externa do etanol: estratégias do estado logístico para inserção internacional dos biocombustíveis brasileiros. (Tesis de doctorado). Universidade de Brasília, Brasília. Recuperado de http://repositorio.unb.br/handle/10482/16989

Vigevani, T. \& Cepaluni, G. (2007). A política externa de Lula da Silva: a estratégia da autonomia pela diversificação. Contexto Internacional, 29(2), 273-335. http://dx.doi.org/10.1590/S0102-85292007000200002

Vizentini, P. G. (2001). Dez anos de Mercosul: A crise da integração e o desafio da ALCA. Revista Indicadores Económicos FEE, 29(1). Recuperado de: https://revistas.dee.spgg.rs.gov.br/index.php/indicadores/article/view/1282

Weber, M. (2008) La ética protestante y el espíritu del capitalismo. México: Fondo de Cultura Económica. 

DOI: https://doi.org/10.24215/24689912e023

BOX, CELESTE: Politóloga y Relacionista Internacional (UCALP), Especialista en Economía Política y Periodismo (UNLP), Magister en Integración Latinoamericana (UNLP) y doctoranda en Comunicación por la UNLP. Docente UNLP y UBA (fsoc). Consultora en instituciones, transparencia y tecnología. Contacto: inboxceleste@gmail.com 